\title{
A Profile for Frequent Emergency Department Users: Determining a Baseline for Targeted Interventions
}

\author{
Barbara Penprase, PhD ${ }^{1}$, RN, CNE, ANEF and Deana Hays, DNP, FNP-BC ${ }^{2}$ \\ Professor, School of Nursing, Endowed Professor, OUSON/Crittenton Hospital Health System , 2002 Human, \\ Health Building, Oakland University, Rochester, MI \\ Interim Associate Dean , 3010 Human Health Building, Oakland University, Rochester, MI
}

\begin{abstract}
Emergency department (ED) services are expensive and often overused by the surrounding community, resulting in overcrowding and strain on healthcare services. ED overuse has been identified as major source of healthcare expenditure and can be as high as 3 times the costs from other healthcare settings To have an effective impact on admissions by ED frequent users, each hospital needs to understand its unique profile and the characteristics of patients who overuse ED services. Only then can an effective program be developed to alleviate their patients' dependency on the ED for care. The purpose of this study was to develop a patient profile of ED frequent users at a mid-sized hopsital in the Midwest.

This research used a descriptive retrospective design to review electronic medical health records of patients with 6 or more visits to the ED within a year. Data were collected for the following demographic information: gender, age, race/ethnicity, primary language, marital status, employment status, zip code, total visits per 12-month time period, time of visit to ED, presenting complaint, length of time in ED, admission to hospital, primary ECD 9 diagnosis, discharge disposition from ED, primary insurance, primary care provider, and reported health status. The research findings supports that older adults, especially females, with chronic illnesses such as CHF, diabetes, and respiratory illnesses are at high risk for becoming frequent users of ED services.

The outcomes of this study are being used to develop a transitional care model program specifically designed for elderly patient with co-morbidities. The program will use a collaborative approach between ED physicians and nurses with nurse practitioner students to see patients not only in the ED but for 60 days following discharge. An overarching expected benefit will be to reduce overall ED costs while increasing patient satisfaction for frequent ED users. Developing programs to assist frequent ED users is imperative to assist elderly patients in coping with their chronic conditions without the reliance of ED services.
\end{abstract}

Key words: Frequent ED Users, Elderly, ED, Transitional Care, ED Patient Profile

\section{INTRODUCTION}

Emergency Departments (EDs) are often considered the "front doors" of hospitals. A large number of patients enter through the ED for services. However, ED services are expensive and often overused by the surrounding community, resulting in overcrowding and strain on healthcare services (Billings \& Raven, 2013; McWilliams, Tapp, Baker, \& Dulin, 2011; Simonet, 2008). ED overuse has been identified as major source of healthcare expenditure andcan be as high as 3 times the costs from other healthcare settings (Wajnberg, Hwang, Torres, \& Yang, 2011).

Overuse of ED services from a small population of patients, referred to as ED frequent users,contribute ssignificantly to the overall disporportionate number of ED visits and total costs(Chan \& Ovens, 2004). ED frequent users account for approximately 9\% of all annual ED visits but contribute to approximately $34 \%$ of all ED costs. (Hardie et al, 2015; Wong, Marr, Kwan, Meiyappan, \& Adcock, 2014).However, just whoED frequent users are remains illusive. Research describing characteristics of ED users varies considerably and is often related to the culture and environment in which the hospital resides. Interventions to curtail use by ED frequent users focus on target populations thatare suspected of frequent use of ED services, such as the uninsured and patients with chronic pain, mental illness and alcohol/drug abuse, and asthma in order to develop programs that support these patients and decrease use of ED services (Baren et al., 2006; Kwack et al., 2004; Liu et al., 2013; Woodhouse, Peterson, Campbell,\& Gathercoal, 2010). However, such characterizations vary considerably for each hospital.

\footnotetext{
${ }^{1}$ Corresponding Author: penprase@oakland.edu
} 
To have an effective impacton admissions by ED frequent users, each hospital needs to understand its unique profileand the characteristics of patients who overuse ED services. Only then can an effective program be developed to alleviate their patients' dependency on the ED for care. The purpose of this study was to develop a patient profile of ED frequent users at a mid-sized hopsital in the Midwest. The outcomes of this study are being used to develop a transitional care model program specifically designed for ED frequent users.

\section{BACKGROUND}

Numerous studies describe demographic ED frequent users characteristics. What defines ED frequent users and factors placing individuals at risk for becoming frequent users are unclear. Published research define many factors affecting patients at risk, such as low socioeconomic status, lack of insurance and primary care services, uninsured, mental illness, alcohol, drug abuse, co-morbidities, insured through Medicaid or Medicare, and other non- frequent users of primary care providers. Recently studies revealed two factors which place patients at high risk for frequent ED use and hospital re-admission: older age (65 years and older) with co-morbidities and complications from prescribed medications. Other research does not support lack of insurance nor primary care providers as major risk factors for ED abuse. (LaCalle \& Rabin, 2010; Tranquada, Denninghoff, King, Davis, \& Rosen, 2010).

\section{METHODS}

This research used a descriptive retrospective design to review electronic medical health records of patients with 6or more visits to the ED within a year (2010 through 2012).

\section{AIM OF THE STUDY}

The intended purpose of this review was to identify the ED frequent user profile to better understand this subset of patients and develop an intervention to decrease use of the ED. An overarching goal was toreduce overall ED costs while increasing patient satisfaction.

\section{Data Analysis}

The data were collected from the ED medical health records at a large Midwestern hospital. For the purpose of this study, 6 visits to the ED in a year or more by the same person was defined as frequent use of ED services. Approximately 1600 files were reviewed for a 2-year,3-monthperiod. The study was deemed exempt by the hospital and university institutional review boards.

Data were collected for the following demographic information: gender, age, race/ethnicity, primary language, marital status, employment status, zip code, total visits per 12-month time period, time of visit to ED, presenting complaint, length of time in ED, admission to hospital, primary ECD 9 diagnosis, discharge disposition from ED, primary insurance, primary care provider, and reported health status. Descriptive statistics were used to determine the highest frequency of risk factors. For continuous variables the mean, standard deviation, medians and ranges were calculated; categorical variables were summarized as frequencies and percentages. Based on ED records data, three data sets were used for this project. These data sets were from 2010 and 2011 (the entire year), plus the first 3 quarters of 2012.

\section{RESULTS}

A total of 1,237 patients met the criteria of 6 or more visits within a 12-month period; they accounted for a total of 9,993 ED visits in the same time frame. Overall, $12 \%$ of the total population were frequent users of the ED. In this group of patients, $42.93 \%$ were between 60 to 75 years of age. Females far outnumbered males $(61.92 \%)$ and most $(87.95 \%)$ were Caucasian. The majority of patients were either married $(31.53 \%)$ or single $(34.76 \%)$ and had Medicare insurance (42.93\%). Thus, the most common ED frequent user profile was a retired Caucasian single adult femalebetween the ages of 60 and 75 with Medicare insurance. The most commonly reported chief complaint for ED frequent users were as follows: back pain $(42.52 \%)$, chest pain $(38.08 \%)$, respiratory problems $(29.75 \%)$, vomiting $(29.75 \%)$, congestive heart failure (CHF)(23.85\%), and headaches(20.53\%). Medical ICD-9 codes reflected the following most common diagnoses: abdominal pain (44.14\%), sprains (26\%), respiratory problems (23.44\%), chest pain (21.99\%), diabetes (19.07\%), CHF (18.35\%), and cellulitis (17.14\%). Refer to Table 1 for further detail.

Table 1:

\begin{tabular}{|l|l|l|l|}
\hline Gender & Male & $38 \%$ & \\
\hline & Female & $62 \%$ & \\
\hline
\end{tabular}


American Research Journal of Nursing, Volume 1, Issue 2, June 2015

ISSN 2379-2922

\begin{tabular}{|c|c|c|c|}
\hline \multirow{6}{*}{ Age } & $0-20$ & $4.2 \%$ & 52 \\
\hline & $21-30$ & $15.36 \%$ & 190 \\
\hline & $41-50$ & $12.85 \%$ & 156 \\
\hline & $51-60$ & $12.05 \%$ & 159 \\
\hline & $61-70$ & $10.43 \%$ & 149 \\
\hline & $>70$ & $32.5 \%$ & 129 \\
\hline \multirow[t]{4}{*}{ Marital Status } & Single & $34.76 \%$ & 402 \\
\hline & Married & $31.53 \%$ & \\
\hline & Divorced & $12.69 \%$ & \\
\hline & Widowed & $19.81 \%$ & \\
\hline \multirow[t]{6}{*}{ Occupation } & Retired & $38.16 \%$ & \\
\hline & Full-time Employment & $8.89 \%$ & \\
\hline & Part-Time Employment & $3.23 \%$ & \\
\hline & Disabled & $16.25 \%$ & \\
\hline & Self-employed & $1.54 \%$ & \\
\hline & Unknown & $1.7 \%$ & \\
\hline \multirow[t]{5}{*}{ Insurance } & Medicare/Medicare Advantage & $52.07 \%$ & \\
\hline & Private & $16.57 \%$ & \\
\hline & Medicaid & $23.11 \%$ & \\
\hline & Self -pay & $8 \%$ & \\
\hline & Workers comp & $0.16 \%$ & \\
\hline \multirow[t]{7}{*}{ Race } & Asian & $0.32 \%$ & \\
\hline & Black & $11.08 \%$ & \\
\hline & Declined & $0.08 \%$ & \\
\hline & Multiracial & $0.32 \%$ & \\
\hline & Native American/Asian & $0.08 \%$ & \\
\hline & Unknown & $0.08 \%$ & \\
\hline & White & $87.95 \%$ & \\
\hline \multirow[t]{3}{*}{ ICD 9} & $72402-7248$ (back pain) & $4.01 \%$ & \\
\hline & $78650-78659$ (chest pain) & $4.44 \%$ & \\
\hline & 4280-42843 (heart failure) & $2.27 \%$ & \\
\hline
\end{tabular}

Admission rates to the hospital within 30 days were very high for frequent ED users; $72 \%$ were admitted within 30 days of a previous ED visit, and 87\% were admitted at least twice within 6 months of the previous ED visit.

\section{DISCUSSION}

Our research supports current literature that older adults are the most likely to use the ED frequently for healthcare needs (Doupe et al., 2012; Roberts, McKay, \& Shaffer, 2008; Sandoval et al., 2010; Wong et al., 2014). As found in the literature, ED frequent users in our study were likely to be insured (Blank et al., 2005; Sandoval et al., 2010; Wajenberg et al., 2011); only $8 \%$ of our population were self-pay. It has been noted that racial differences maybe a contributing factor for ED frequent use and thatAfrican Americans have been found to have higher rates of ED use compared to whites (Roberts et al., 2008; Sandoval et al., 2010; Wajenberg et al. 2011). However, we found that $87 \%$ of ED frequent users in our study were Caucasian, reflecting the predominately Caucasian population served by this hospital.

Although cellulites were a frequently used ICD-9 code, the data were not clear as to where the cellulites occurred, except for a small population with renal failure. Although abdominal pain was commonly reported by patients and by ICD-9 codes, the pain varied considerably and accompanied nausea, vomiting, diarrhea, and urinary tract infections; therefore, the reported percentages for both ICD-9 codes and chief complaint were somewhat misleading. The findings indicated that older adult ED frequent users had at least one of the following chronic conditions: chest pain, diabetes, heart failure, respiratory problems, and abdominal pain. Heart failure and diabetes were also found in two prior studies to contribute to frequent ED use by older adults (Doupe et. al., 2012; Wajenburg et. al., 2011).More recent research supports that chronic illness appears to be a risk factor for ED frequent use (Bieler et al., 2012; Doupe et al., 2012; Sandoval et al., 2010; Wajenburg et al., 2011). This research also did not support drugrelated factors as a significant factor for frequent ED use as reported by Wong et al. (2014). 
One of the most important findings in this study was that frequent ED use correlates with high admission rates to the hospital. This supports the findings of other research indicating thathospital admission rates are higher for frequent ED users when compared to no frequent users (Funda \& Immekus, 2006; Roberts, McKay, \& Shaffer, 2007). One limitation of the data was the lack of information regarding secondary diagnoses and co-morbidities. It is speculated that frequent users will have at least 2 co-morbidities, and most likely more, based on current research findings (Doupe et al., 2012; Roberts et al., 2007; Sandoval et al., 2010; Wong et al., 2014). Also, the research was conducted in one community and needs to be repeated in other community settings. This research supports that individual hospitals' ED frequent user profiles will differ due to a variety of different environmental factors.

\section{NEXT STEPS}

Developing programs to assist frequent ED users is imperative to assist patients in coping with their chronic conditions. The research findings from this study, and from a second study that focused on a subset of this population (Hays \& Penprase, 2015),have been used to develop a program based on transitional care for ED frequent users. For this program, nurse practitioner students screen patients in an ED observational unit and identify patients atrisk for frequent ED use. Patients are then followed for 60 days through home visits and phone calls by the NP students. The program is being implemented at this hospital and the research has been expanded to include two other hospitals in the Midwest. Interventions that focus on transitioning the patient from hospital to home have been proven to be effective in reducing readmission rates in geriatric populations and reducing costs for the hospital (Benbassat and Taragin, 2000; Coleman et al., 2006; Naylor et al., 1994 \& 1994; Naylor et al, 2004), but no studies have focused specifically on ED populations.

\section{SUMMARY}

The findings from this study support the need for hospitals to understand the unique characteristics of their ED frequent users. Only by understanding the ED frequent user profile can a program be designed to curtail ED use and hospital admissions to unique populations. This research supports that older adults, especially females, with chronic illnesses such as CHF, diabetes, and respiratory illnesses are at high risk for using the ED for healthcare.Resulting from this research findings has been the development and pilot of a transitional care program that focuses on elderly patients (60 years and older) with co-morbidities who use the ED services. ED physicians, staff and nurse practitioner (NP) students work closely to identify high risk patients profiled as potential frequent ED users. The NP students then follow the patients for 60 days after discharge from the ED services in their home.

\section{REFERENCES}

[1] Baker, L. C., \& Baker, L. S. (1994). Excess cost of emergency department visits for no urgent care. Health Affairs, 13(5), 162-171.

[2] Baren, J. M., Boudreaux, E. D., Brenner, B. E., Cydulka, R. K., Rowe, B. H., Clark, S. \& Camargo, C. A. (2006). Randomized controlled trial of emergency department interventions to improve primary care followup for patients with acute asthma. Chest, 129(2), 257-265.

[3] Bieler, G., Paroz, S., Faouzi, M., Trueb, L., Vaucher, P., Althaus, F., Daeppen, J., \&Bodenmann, P. (2012). Social and medical vulnerability factors of emergency department frequent users in a universal health insurance system. Academic Emergency Medicine, 19(1), 63-68. doi: 10/1111/j.1553-2712.2011.01246.x

[4] Billings, J., \& Raven, M. (2013). Dispelling an urban legend: Frequent emergency department users have substantial burden of disease. Health Affairs, 32(12), 2099-2108.

[5] Blank, F. S., Li, H., Henneman, P. L., Smithline, H., Santoro, J. S., Provost, D., \& Maynard, A..M. (2005). A descriptive study of heavy emergency department users at an academic emergency department reveals heavy ED users have better access to care than average users. Journal of Emergency Nursing, 31, 139-144. doi: 10.1016/j.jen.2005.02.008

[6] Chan, B. T. \& Oven, H. (2004). Chronic migraineurs: An important subgroup of patients who visit emergency departments frequently. Annals of Emergency Medicine, 43(2), 238-242.

[7] Doupe, M. B., Palatnick, W., Day, S., Chateau, D., Soodeen, R., Burchill, C., \& Derksen, S. (2012). Frequent users of emergency departments: Developing standard definitions and defining prominent risk factors. American College of Emergency Physicians, 60(1), 24- 32. doi:10.1016/j.annemergmed.2011.11.036

[8] Fuda K. K. , Immekus R. (2006). Frequent users of Massachusetts emergency departments: a statewide analysis. Annals of Emergency Medicine, 48, 9-16.

[9] Grumbach, K., Keane, D., Bindman, A. (1993). Primary care and public emergency department overcrowding. American Journal of Public Health, 83, 372-378. 
[10] Hardie, T., Polek, C., Wheeler, E., McCamant, K., Kixson, M., Gailey, R., \& Lafrak, K. (2015). Characterising emergency department high-frequency users in a rural hospital. Emergency Medicine Journal, 32(1), 21-5.

[11] Hays, D., \& Penprase, B. (2015) Risk factors in older adults' emergency department frequent users. Unpublished manuscript.

[12] Kwack, H., Sklar, D., Skipper, B., Kaufman, A., Fingado, E. \& Hauswald, M. (2004). Effect of managed care on emergency department use in uninsured population. Annals of Emergency Medicine, 43(2), 166-173.

[13] LaCalle, E., \& Rabin, E. (2010). Frequent users of emergency departments: the myths, the data, and the policy implications. Ann Emerg Med., 56. 42-48.

[14] Lui, S., Nagurney, J., Change, Y., Parry, B., Smulowitz, P., \& Atlas, S. (2013). Frequent ED users: Are most visits for mental health, alcohol, and drug-related complaints? American Journal of Emergency Medicine, 31(10), 1512-1515.

[15] McWilliams, A., Tapp, H., Barker, J., \& Dulin, M. (2011). Cost analysis of the use of emergency departments for primary care services in charolette north Carolina. NC Medical Journal,72(4), 265-271.

[16] Naylor, M., Brooten, D., Cambell, R., Jacobson, B. S., McCauley, K.M., \& Schwartz, J. S. (2004). Transitional care model for older adults hospitalized with heart failure: A randomized clinical trial. JAGS, 52(5). 675-684.

[17] Naylor, M., Brooten, D., Cambell, R., Jacobson, B. S., Mezey, M. D., Pauly, M. V., \& Schwartz, J.S. (1999). Comprehensive discharge planning and home follow-up of hospitalized elders: A randomized control trial. JAMA, 281(7). 613-620.

[18] Naylor, M., Brooten, D., Jones, R., Lavizzo-Maourey, R., Mezey, M., \& Pauly, M. (1994). Comprehensive discharge planning for the hospitalized elderly: A randomized clinical trial. Annals of Internal Medicine, 120(12), 999-1006.

[19] Pane, G. A., Farner, M. C., \& Saleness, K. C. (1991). Health care access problems of medically indigent walkin patients. Annals of Emergency of Medicine, 20, 270-273.

[20] Roberts D. C., McKay M. P., \& Shaffer, A. (2008). Increasing rates of emergency department visits for elderly patients in the United States, 1993 to 2003. Annals of Emergency Medicine51(6), 769-74. doi:10.1016/j.annemergmed.2007.09.011

[21] Sandoval, E., Smith, S., Walter, J., Schuman, S. H., Olson, M. P., Striefler, R., Brown, S., \& Hickner, J. (2010). A comparison of frequent and infrequent visitors to an urban emergency department. The Journal of Emergency Medicine, 38(2), 115-121. doi:10.1016/j.jemermed.2007.09.042

[22] Simonet, D. (2008). Cost reduction strategies for emergency services: Insurance role, practice changes, and patients accountability. Health Care Anal, 17, 1-19. doi:10.1007/s10728 008-0081-0

[23] Tranquada, K. E., Denninghoff, K. R., King, M. E., Davis, S. M., \& Rosen, P. (2010) Emergency department workload increase: Dependence on primary care. The Journal of Emergency Medicine, 38(3), 279-285. doi:10.1016/j.jemermed.2008.11.031

[24] Wajenburg, A., Hwang, U., Torres, L., \& Yang, S. (2011). Characteristics of frequent geriatric users of an urban emergency department. The Journal of Emergency Medicine, 43(2), $\quad 376-381$. doi:10.1016/j.jemermed.2011.06.056

[25] Wong, J., Marr, P., Kwan, D., Meiyappan, S., \& Adcock, L. (2014). Identification of inappropriate medication use in elderly patients with frequent emergency department visits. Canadian Pharmacists Journal, 147(4), 248-256.

[26] Woodhouse, J., Peterson, M., Campbell, C. \& Gathercoal, K. (2010). The efficacy of a brief behavioral health intervention for managing high utilization of ED services by chronic pain patients. Journal of Emergency Nursing, 36(5), 399-403. 